\title{
Nature and Energies of Electrons and Holes in a Conjugated Polymer, Polyfluorene
}

\author{
Norihiko Takeda, Sadayuki Asaoka, and John R. Miller*
}

Chemistry Department, Brookhaven National Laboratory, Upton, New York 11973-5000

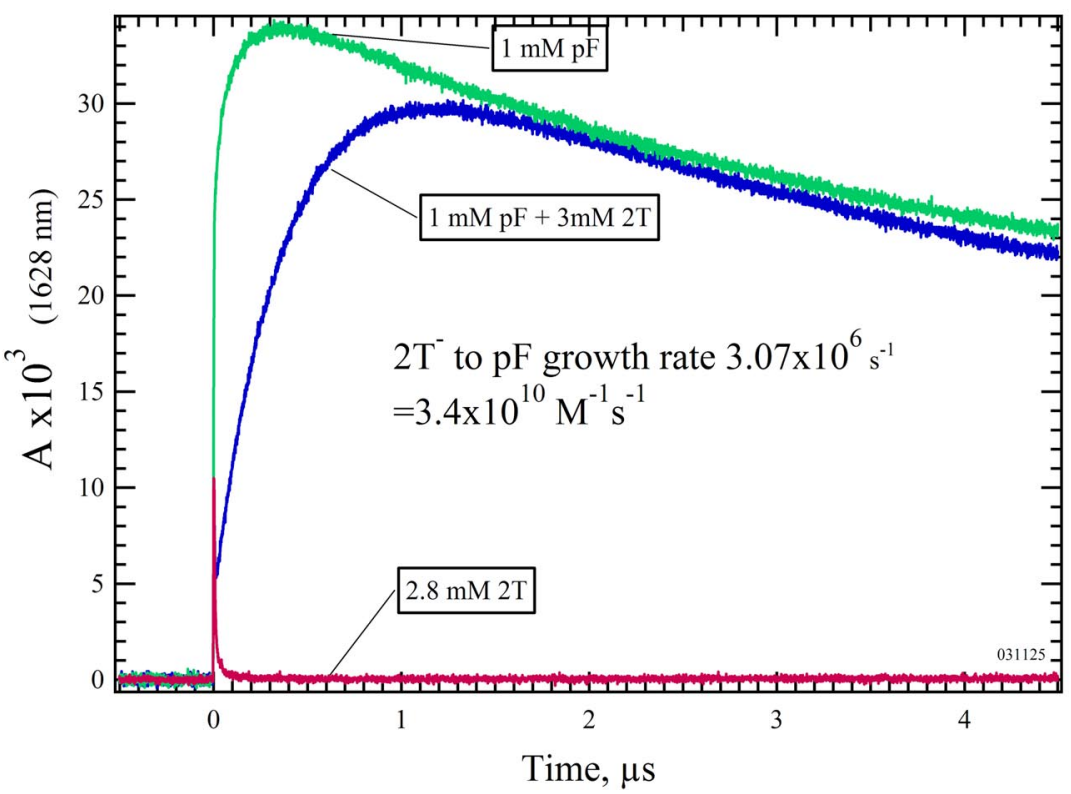

Figure S-1 Transient absorption traces at $1628 \mathrm{~nm}$ in solutions of $1 \mathrm{mM} \mathrm{pF}$ and $1 \mathrm{mM} \mathrm{pF}+3 \mathrm{mM}$ bithiopehene (2T) in THF. The red trace $(2.8 \mathrm{mM} 2 \mathrm{~T})$ shows that the $2 \mathrm{~T}$ anion does not absorb at the wavelength; only rapid decay of solvated electrons is seen.

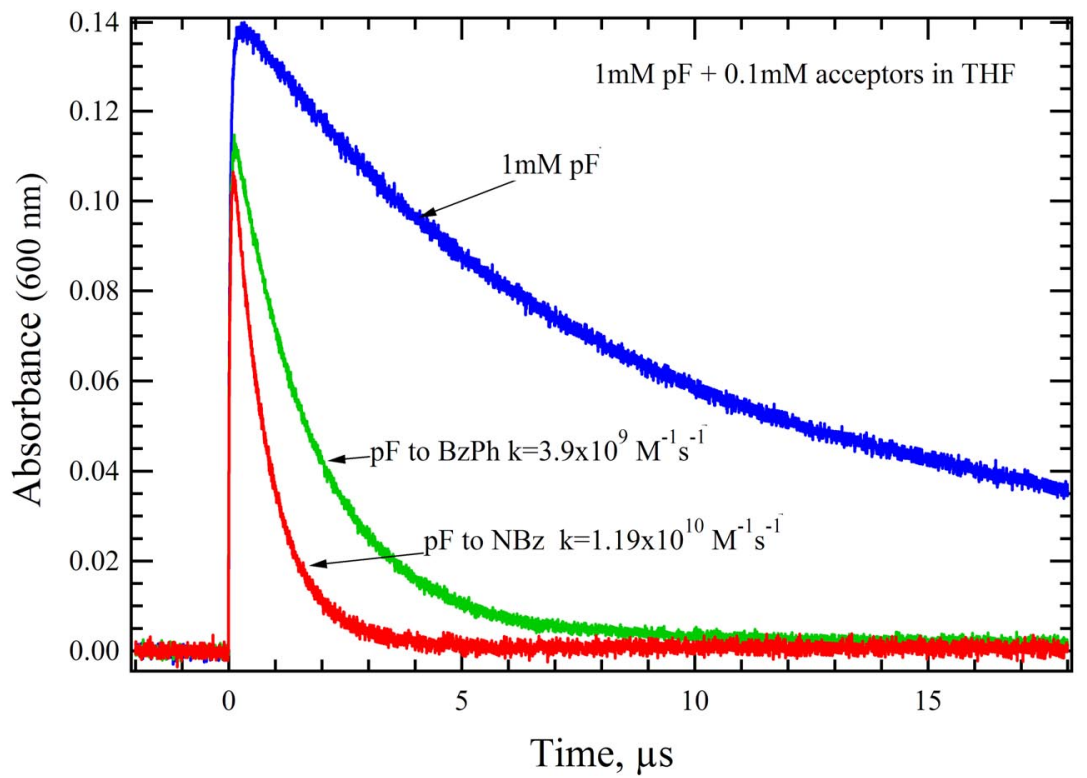

Figure S-2 Transient absorption traces at $600 \mathrm{~nm}$ in solutions of $1 \mathrm{mM} \mathrm{pF}$ and without and with $0.1 \mathrm{mM}$ benzophenone (BzPh) or nitrobenzene (NBz) in THF.

030731 


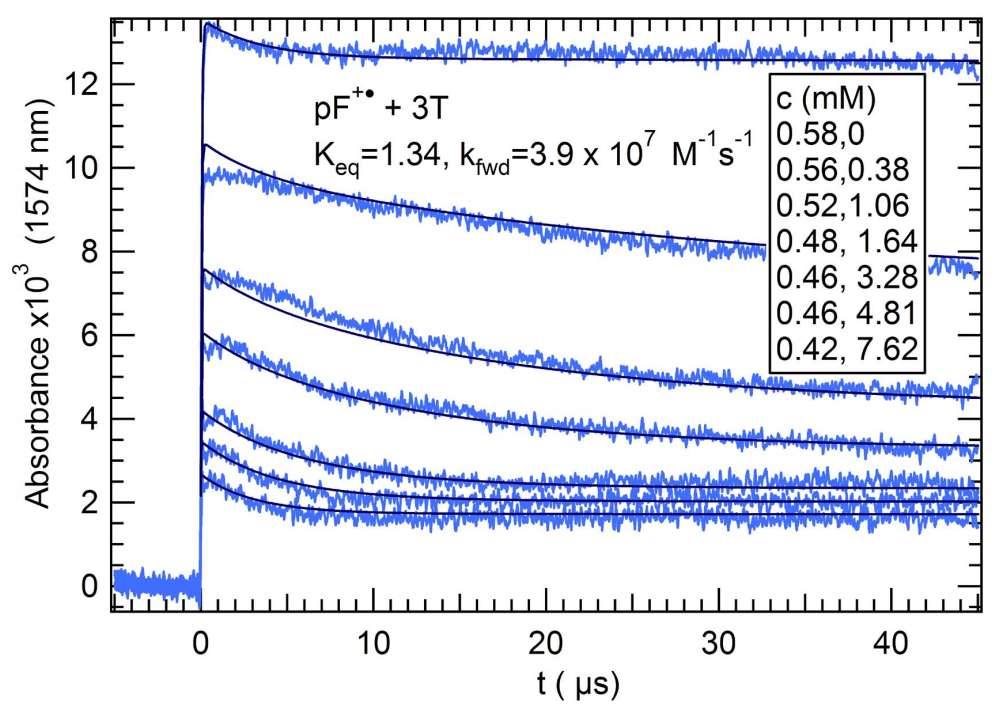

Figure S-3 Transient absorption traces at $1574 \mathrm{~nm}$ in solutions of $\mathrm{pF}$ with varied concentrations of terthiophene (3T) in 1,2-dichloroethane. 05-02-11_2b

\section{Derivations of eqs 1 and 2 for estimation of charge delocalization length $I_{n}$}

Figure S-4 illustrates a pF ion created from injection of single charge (positive or negative) delocalized over $I_{n}$ monomer units. Production of ions ([ions]) is accompanied by bleaching of $I_{n}$ times number of monomer units $\left(\left[f_{1}\right]\right)$ as expressed in eq 1.

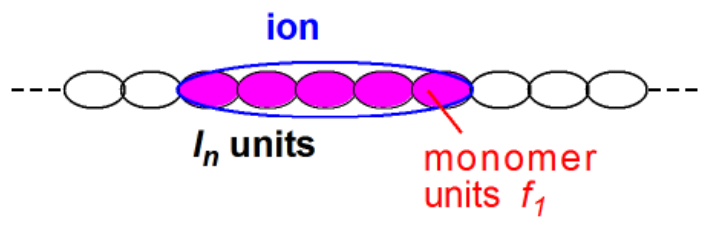

Figure S-4 Charge delocalization length $I_{n}$ of an ion and bleaching monomer units $f_{1}$.

The $I_{n}$ for $\mathrm{pF}$ anions was estimated using spectroscopic data in figures 3 and 4 . Derivatives of concentrations of bleaching neutral monomer units $\left(-d\left[p F_{1}\right]\right)$ and those of growing anions $(d[p F$ •]) were evaluated using absorption bands at $382 \mathrm{~nm}$ and $600 \mathrm{~nm}$, respectively.

Here the experimentally observed difference absorbances at each band (figure 3 ) could have contributions from both anions and neutral units.

For bleaching neutral units,

$$
-d\left[p F_{1}\right]=\frac{d A_{382}}{\frac{d A_{382}}{-d\left[p F_{1}\right]}}=\frac{d A_{382}}{\frac{d A_{382}^{\text {neutral }}+d A_{382}^{\text {anion }}}{-d\left[p F_{1}\right]}}=\frac{d A_{382}}{\frac{d A_{382}^{\text {neutral }}}{-d\left[p F_{1}\right]}+\frac{1}{l_{n}} \frac{d A_{382}^{\text {anion }}}{d\left[p F^{-\bullet}\right]}}
$$

For growing anions,

$$
d\left[p F^{-\bullet}\right]=\frac{d A_{600}}{\frac{d A_{600}}{d\left[p F^{-\bullet}\right]}}=\frac{d A_{600}}{\frac{d A_{600}^{\text {anion }}+d A_{600}^{\text {neutral }}}{d\left[p F^{-\bullet}\right]}}=\frac{d A_{600}}{\frac{d A_{600}^{\text {anion }}}{d\left[p F^{-\bullet}\right]}-l_{n} \frac{d A_{600}^{\text {neutral }}}{d\left[p F_{1}\right]}}
$$

Inserting eqs $\mathrm{S} 1$ and $\mathrm{S} 2$ into eq 1 gives eq 2 . A term $-d A_{382} / d A_{600}$ in eq 2 can be evaluated from the inverse of the slope of lines in figure 4. Extinction coefficients of both anions and neutral units at each absorption band must be known from separate experiments to derive $I_{n}$, as given in Table 
1. Note that similar derivations are possible using anion bands at other wavelengths such as $2480 \mathrm{~nm}$.

\section{Use of the Born equation to estimate solvation energies as a function of polarity.}

The Born equation gives the free energy of solvation for a singly charged sphere of radius $r_{\text {Born }}$ in a dielectric continuum of dielectric constant $\varepsilon_{\mathrm{s}}$,

$$
\Delta G_{\mathrm{S}}=-e^{2}\left(1-1 / \varepsilon_{\mathrm{S}}\right) / 2 r_{\text {Born }}
$$

where $\Delta G_{\mathrm{s}}$ is the difference between the total solvation energies of the ion and neutral and $\mathrm{e}$ is the electronic charge. A first need is an estimate of the effective spherical radius, $r_{\mathrm{Born}}$, which can represent the non-spherical molecules. Here we estimate $r_{\text {Born }}$ for pyrene by assuming that the sum of solvation free energies for pyrene radical cation and anion under electrochemical conditions are given by the double difference between the reversible electrochemical redox potentials and the corresponding gas phase ionization potential $(I P)$ and electron affinity $(E A)$ :

$$
\Delta G_{s}\left(\mathrm{Py}^{+\bullet}\right)+\Delta G_{s}\left(\mathrm{Py}^{-\bullet}\right)=E^{0}\left(\mathrm{Py}^{+/ 0}\right)-E^{0}\left(\mathrm{Py}^{0 /-}\right)-[I P-E A]
$$

The redox potentials $E^{0}\left(\mathrm{Py}^{+/ 0}\right)=+0.87$ (in $\mathrm{SO}_{2}, \varepsilon_{\mathrm{S}}=20$ at $\left.-40^{\circ} \mathrm{C}\right)^{\mathrm{S} 1}$ and $E^{0}\left(\mathrm{Py}^{0 /-}\right)=-2.63 \mathrm{~V}$ (in THF, $\left.\varepsilon_{\mathrm{s}}=7.6\right)$, both vs $\mathrm{Fc}^{+/ 0}$, and the $I P=7.43$ and $E A=0.5 \mathrm{eV}^{\mathrm{S} 2}$ gave $-1.715 \mathrm{eV}$ as the solvation free energy of pyrene ions. This is an average for $\mathrm{Py}^{+\bullet}$ and $\mathrm{Py}^{-}{ }^{-}$. When electrolyte is present the lower dielectric constant of THF gives modest differences in potentials: $E^{0}\left(\right.$ fluorenone $\left.e^{0 /-}\right)-E^{0}\left(\mathrm{Fc}^{+/ 0}\right)$ was $-1.82 \mathrm{~V}$ in THF and $-1.71 \mathrm{~V}$ in acetonitrile when both contained $0.1 \mathrm{M} \mathrm{TBABF}_{4}$., leading to an estimate that solvation energies, including the effects of the electrolyte, are $55 \mathrm{meV} / \mathrm{ion}$ larger (more negative) in acetonitrile than in THF. Taking this small change as an estimate for the effect of the lower dielectric constants on the potentials of pyrene, we obtain $-1.715-0.055=-1.77 \mathrm{eV}$ as the average solvation energy for ions in highly polar solvents like acetonitrile $\left(\varepsilon_{\mathrm{s}}=38\right)$, containing electrolyte, corrected to $-1.76 \mathrm{eV}$ without electrolyte (Figure S-5).

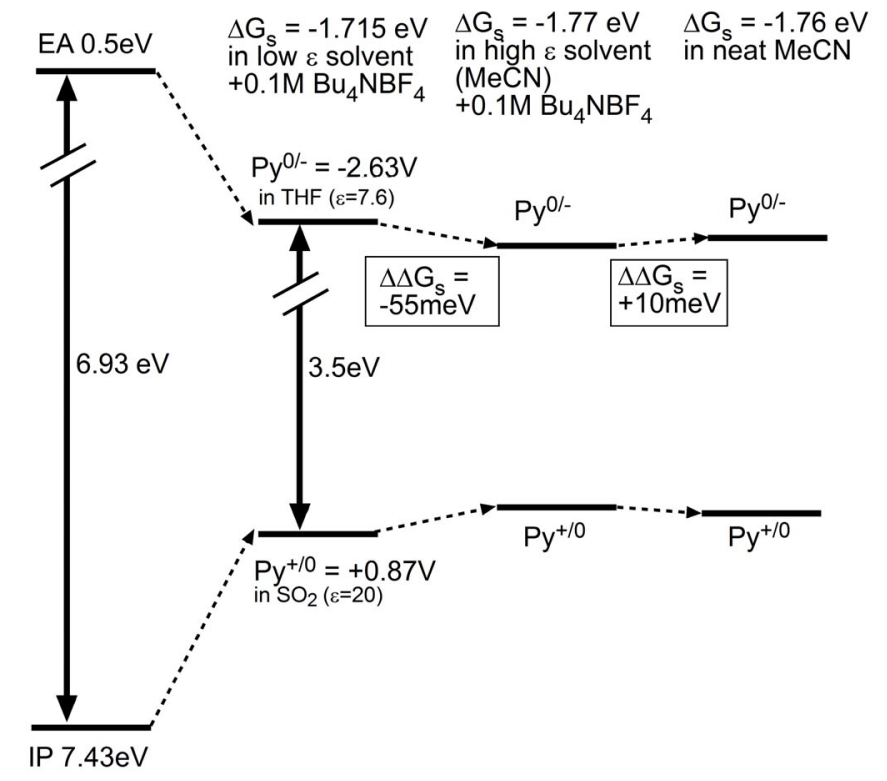

Figure S-5 An energy diagram for estimation of average solvation energies of pyrene ions (anions and cations) in non-polar and polar solvents with $0.1 \mathrm{M} \mathrm{Bu}_{4} \mathrm{NBF}_{4}$ supporting electrolytes, and in highly polar neat solvents (acetonitrile). 
For this solvation energy the Born equation gave $r_{\text {Born }}=0.399 \mathrm{~nm}$ for pyrene. With this $r_{\text {Born, }}$, the solvation free energy to create a pair of $\mathrm{Py}^{+\bullet}$ and $\mathrm{Py}^{-\bullet}$ ions in THF $\left(\varepsilon_{\mathrm{s}}=7.6\right)$ is then estimated to be $-3.14 \mathrm{eV}$ vs. -3.43 under electrochemical conditions $\left(\mathrm{THF}+0.1 \mathrm{M} \mathrm{Bu}_{4} \mathrm{NBF}_{4}\right)$ : creation of a pair of $\mathrm{Py}^{+\bullet}, \mathrm{Py}^{-\bullet}$ ions at infinite distance requires $0.29 \mathrm{eV}$ more energy in pure THF than under electrochemical conditions. A good value for $I P($ terthiopehene) was not found, so we assumed that this change in solvation energy for terthiopehene ${ }^{+\bullet}$ is similar to that for $\mathrm{Py}^{+\bullet}$.

The free energy to create a pair of $\mathrm{pF}^{+\bullet}$ and $\mathrm{pF}^{-\bullet}$ ions in THF/DCE increases by a smaller amount because the delocalized $\mathrm{pF}$ ions interact less with the polar media (including electrolyte ions). This change is $78 \mathrm{meV} /$ ion, or $156 \mathrm{meV}$ for a pair, from the free energy changes given in table 2 of the paper, where equilibrium was also obtained in THF with and without electrolyte. From these data the energy to create a pair of $\mathrm{pF}^{+\bullet}$ and $\mathrm{pF}^{\bullet}$ ions rises by $0.29-0.156-=0.13 \mathrm{eV}$ in THF.

These changes are illustrated in Figure S-6. From these differences the solvation free energies to form $\mathrm{pF}^{+\bullet}$ and $\mathrm{pF}^{\cdot}$ ions are $45 \%$ of those for pyrene ions and for $\mathrm{pF}$ ions the Born radius is $r_{\text {Born }}=0.89 \mathrm{~nm}$.

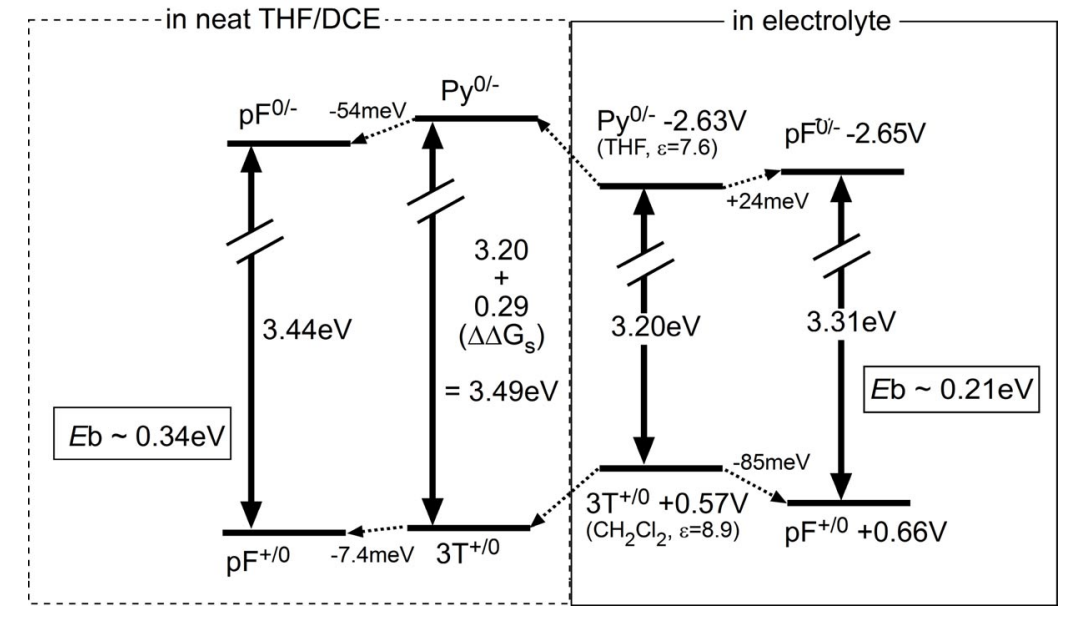

Figure S-6 Estimates for free energies to form $\mathrm{pF}^{+\bullet}$ and $\mathrm{pF}^{\bullet}$ ions in THF (extreme left) from those measured in the presence of electrolyte (far right) utilizing measured equilibria and electrochemical potentials for pyrene and terthiophene (center right) and estimates of the Born equation. The exciton binding energy $\left(E_{\mathrm{b}}\right)$ in neat solvents could increase from the $E_{b}$ evaluated in electrolyte solutions as indicated.

\section{References}

S1. Dietrich, M.; Heinze, J., J. Am. Chem. Soc.1990, 112, 5142-5145.

S2. NIST Chemistry Web Book. http://webbook.nist.gov/chemistry/. 